\title{
Involvement of homocastasterone, salicylic and abscisic acids in the regulation of drought and freezing tolerance in doubled haploid lines of winter barley
}

\author{
Sabina Malaga ${ }^{1} \cdot$ Anna Janeczko ${ }^{1}$. Franciszek Janowiak ${ }^{1}$ Piotr Waligórski ${ }^{1} \cdot$ Jana Oklestkova $^{3} \cdot$ Ewa Dubas $^{1}$. \\ Monika Krzewska ${ }^{1}$ Anna Nowicka ${ }^{1,4}$ - Ewa Surówka ${ }^{1}$ Marcin Rapacz ${ }^{2}$ - Magdalena Wójcik-Jagła ${ }^{2}$. \\ Przemysław Kopeć ${ }^{1} \cdot$ Tomasz Hura $^{1}$ • Agnieszka Ostrowska ${ }^{1} \cdot$ Katarzyna Kaczanowska $^{1} \cdot$ Iwona Żur $^{1}$ (D)
}

Received: 17 April 2019 / Accepted: 30 September 2019 / Published online: 19 October 2019

(c) The Author(s) 2019

\begin{abstract}
Ten doubled haploid (DH) lines of winter barley with an increased range of freezing/drought tolerance were used to identify phytohormones involved in plant stress acclimation. Cold hardening and drought stress were applied at the most critical stages of plant development on young seedlings and heading plants, respectively. The level of the phytohormones was significantly higher at heading, more than 5-fold in respect of salicylic acid (SA) and total brassinosteroids (BRs) and 1.7-fold in the case of abscisic acid (ABA). Moreover, the spectrum of detectable BRs increased from one-homocastasterone (HCS) - found in seedlings to four BRs identified in heading plants [HCS, castasterone (CS), teasterone and dolicholide], with the last one detected for the first time in cereal species. To some extent freezing tolerance seems to be determined by native hormonal status as control seedlings of tolerant DH lines contained 1.4- and 2.3-fold lower amount of ABA and HCS and 2.3-fold higher amount of SA in comparison to freezing-sensitive ones. Such dependency was not observed in heading plants as significant variation in CS content was the only detected difference. Under stress treatments, tolerant DH lines accumulated significantly lower (75-81\%) amount of ABA, which probably reflected lower stress intensity resulting from another defence strategy. In contrast, stress-induced significant almost 2-fold increase in HCS/CS and 2-3-fold decrease in SA content specific for tolerant DH lines of barley suggest the involvement of these molecules in freezing/drought defence. Detected correlations suggest their interaction with nonspecific peroxidase and low molecular weight antioxidants.
\end{abstract}

Keywords Environmental stress acclimation $\cdot$ Homozygous lines $\cdot$ Hordeum vulgare (L.) $\cdot$ Phytohormones

Iwona Żu

i.zur@ifr-pan.edu.pl

1 The Franciszek Górski Institute of Plant Physiology, Polish Academy of Sciences, Niezapominajek 21, 30-239 Kraków, Poland

2 Department of Plant Physiology, University of Agriculture in Kraków, Podłużna 3, 30-239 Kraków, Poland

3 Laboratory of Growth Regulators, Faculty of Science, Institute of Experimental Botany \& Palacký University, The Czech Academy of Sciences, Šlechtitelů 27, 78371 Olomouc, Czech Republic

4 Institute of Experimental Botany of the Czech Academy of Sciences v. v. i. (IEB), Centre of the Region Haná for Biotechnological and Agricultural Research (CRH), Šlechtitelů 31, 78371 Olomouc, Czech Republic

\section{Introduction}

Hormones are the key factors regulating all aspects of life of any living organism starting from the process of egg cell fertilization and embryo development, up to senescence and death. Apart from their role in development and basic metabolism, another crucial role played by these compounds is the acclimation of living organisms to changing environment (Verma et al. 2016; Wani et al. 2016). In the animal kingdom, any life-threatening situation induces a cascade of near-instantaneous hormonal changes determining which of the 'fight-or-flight' responses is chosen (Dhabhar 2018). Also plants evolved survival mechanisms harnessing various types of phytohormones to integrate stress signals and to control downstream stress responses aimed at acclimation and/or adaptation to adverse environment (Deveraj and Dsouza 2018). 
Among several 'stress hormones' abscisic acid (ABA) is the most often examined and correlated with the level of stress tolerance. It is due to the fact that unfavourable environmental conditions such as drought, salinity, cold, heat stress and wounding induce a dramatic increase in ABA accumulation (Fujii 2014; Vishwakarma et al. 2017). ABA plays several key roles in the regulation of a plant's life cycle and its environmental response (Hirayama and Shinozaki 2007). Regulation of seed dormancy and response to water deficit, specifically the regulation of stomata movement, seem to be the most characteristic (Trejo et al. 1995; Kalemba et al. 2009; Nambara et al. 2010). It is worth noting that in both cases the mechanisms of biochemical defence against dehydration, characteristic for the action of virtually all stress factors, are activated.

The main role of another stress hormone-salicylic acid (SA) - is mainly associated with systemic acquired resistance (SAR; Vlot et al. 2009) though the signalling role played in defence against biological agents is not the only one. There are also abiotic stress reactions in which this phenolic compound seems to be actively engaged (Khan et al. 2015), possibly through the regulation of defencerelated genes expression and metabolism of molecules involved in plant defence response (heat shock proteins, proline, betaines) and/or activation of the antioxidative system. Whereas the positive effect of exogenous SA application on plant tolerance to abiotic stresses such as salinity, osmotic, drought and heat stress was often reported (Hayat et al. 2010; Khan et al. 2015), the effect of endogenous SA content and the general model of its function in abiotic stress tolerance is still under investigation.

The main emphasis in this study was put on another group of compounds - brassinosteroids (BRs) - belonging to a relatively new class of plant steroid hormones. The group comprises about 70 compounds with different structure, physiological activity and distribution (Zullo and Kohout 2004; Bajguz 2007). The type and concentration of BRs depend on the plant species (or even cultivar), organ and plant age (Janeczko and Swaczynova 2010; Janeczko et al. 2010). Their role in abiotic stress alleviation was proven for various crop species growing under drought, salinity and low temperature stress (Bajguz and Hayat 2009). In the case of the last one (frost), the mechanism of BR action is connected with the regulation of the expression of COR (coldresponsive) genes (Eremina et al. 2016).

During evolution, the accuracy and efficiency of stress defence has been predestining the success of a particular plant species. This natural process was disturbed by domestication and conventional breeding, which diminished biological variation and resulted in the production of highyield, high-input cultivars with decreased environmental acclimation ability (Liu et al. 2019). Based on transcriptome data it was shown that domestication and artificial selection affected the pattern of variation in gene expression throughout the genome and decreased the expression diversity across several examined animal and plant species. This problem concerns especially barley (Hordeum vulgare L.), one of the first domesticated plant species, which still remains one of the world's most important cereal crops. Due to low freezing tolerance the cultivation of its winter forms is limited to regions with temperate climate. Even there, more severe winter conditions usually result in serious plant damages and yield losses. Another problem is high sensitivity to drought occurring in the so-called 'critical periods' i.e. heading, blooming and seed setting phases, which is another major factor causing a substantial reduction of yield and a decrease in its quality. Despite extensive studies focused on the identification of factors that determine high freezing and drought tolerance, breeding progress is still not satisfactory. It could be explained by the fact that tolerance to both stress factors is based on a complex network of polygenic traits with strong interactions between the genotype and environment (Busconi et al. 2001; Ceccarelli et al. 2010). As changes in temperature extremes and water scarcity connected with climate warming and human activity are considered key threats for the twenty-first century, the understanding of stress tolerance mechanism and the production of improved cereal crops is one of the most important challenges facing scientists and breeders.

Fortunately, some biotechnological tools, e.g. doubled haploid (DH) technology, give the unique possibility to increase low genetic variation, speed up the breeding progress and keep up with the demands of agricultural market and environmentally friendly farming systems. The induction of sporophytic development in haploid plant cells (microspores) followed by further diploidization of chromosome numbers allows for instant production of totally homozygous lines from heterogeneous parents. It also enhances the level of genetic variation due to the expression of recessive alleles and new pleiotropic or epistatic interactions (Humphreys et al. 2007). In order to increase genetic diversity in the level of drought and freezing tolerance, the population of $1090 \mathrm{DH}$ lines of winter barley was produced from Polish breeding materials of $\mathrm{F} 1$ generation. The population was phenotyped and ten extreme DH lines were identified and examined previously in respect of changes in the functioning of the photosynthetic apparatus, antioxidative system activity and proteomic profiles induced in the response to low temperature and drought (GołębiowskaPikania et al. 2017a, b).

In this study, to verify the hypothesis of the involvement of the above-mentioned phytohormones and their interaction with the elements of the antioxidative system in plant defence and stress tolerance acquisition/ability, cold- and drought-induced changes in the content of ABA, SA and some BRs were investigated with the use of selected DH 
lines of winter barley. Another aim of the study was to recognize which of the defence reactions and factors regulating plant acclimation to freezing and drought were universal or specific for a particular stress.

\section{Material and methods}

\section{Plant material}

DH lines of winter barley used in the study were produced from valuable breeding materials of $\mathrm{F} 1$ generation of winter barley (H. vulgare L.) which were obtained from DANKO Plant Breeding (Choryń, Poland) and Strzelce Plant Breeding (Strzelce, Poland) companies. For the production of DH lines we used anther culture method according to the modified protocols of Jacquard et al. (2003) and Cistue et al. (2003), as it was described in Malaga et al. (2016). The produced population of DH lines showed an increased level of variation in freezing and drought tolerance level and provided valuable genetic resource for breeding programs.

DH lines used in the study were selected on the basis of standard laboratory tests described in detail by GołębiowskaPikania et al. (2017a, b). On the basis of the results received from freezing tolerance test (percentage of plant survival after $8 \mathrm{~h}$ at $-12{ }^{\circ} \mathrm{C}$ ) according to the procedure described by Rapacz et al. (2011), the DH lines of barley used in this experiment were identified as (1) freezing tolerant: DH602 and DH534, (2) moderately tolerant: DH561, DH61, DH435 and DH584 and (3) freezing susceptible: DH65, DH158, DH575 and DH363 (Fig. 1).
The estimation of drought tolerance was performed according to Hura et al. (2017) based on leaf water content (LWC) and leaf water loss (LWL) parameters according to the following equations:

$$
\begin{aligned}
& \mathrm{LWC}=\left(\left(\mathrm{L}_{\mathrm{FM}}-\mathrm{L}_{\mathrm{DM}}\right) / \mathrm{L}_{\mathrm{FM}}\right) \times 100 \%, \\
& \mathrm{LWL}=\left[\left(\mathrm{LWC}_{\mathrm{C}}-\mathrm{LWC}_{\mathrm{DT}}\right) / \mathrm{LWC}_{\mathrm{C}}\right] \times 100 \%,
\end{aligned}
$$

where $\mathrm{L}_{\mathrm{FM}}$ is leaf fresh mass, $\mathrm{L}_{\mathrm{DM}}$ is leaf dry mass after $72-\mathrm{h}$ lyophilization, $\mathrm{LWC}_{\mathrm{C}}$ is leaf water content of control plants, $\mathrm{LWC}_{\mathrm{DT}}$ is leaf water content of drought-treated plants.

Among the studied plant materials: (i) drought tolerant (DH534, DH561 and DH584), (ii) moderately tolerant (DH363, DH65, DH61, DH158, DH575) and (iii) drought sensitive (DH602, DH435) DH lines were identified (Fig. 1).

The selected DH lines were derived from the following parental materials: DH534 (Traminer $\times$ Franziska), DH561 (POA 3574/92/1 × Rosita), DH575 (POA 03/260 $\times$ Lomerit), DH584 (POA 03/260× Rosita), DH602 (cv Souleyka, Saaten Union, Germany), DH61, DH65, DH363 (POA 7020/06 - $2 \times$ Gloria), DH158 (Maybrit $\times$ RAH 983) and DH435 (POA 7209/06 - 3× RAH 978).

\section{Experiment 1. Conditions of plant growth, cold hardening and sampling}

Seeds were sown in plastic boxes $(30 \mathrm{~cm} \times 38 \mathrm{~cm} \times 9 \mathrm{~cm})$ filled with a mixture of sand, clay soil and peat (1/1/1, $\mathrm{v} / \mathrm{v} / \mathrm{v})$ and germinated for 4 days in darkness, at constant temperature of $25{ }^{\circ} \mathrm{C}$. Next, plant growth was maintained at $25 / 17{ }^{\circ} \mathrm{C}$ (day/night), $12 / 12 \mathrm{~h}$ (day/night)

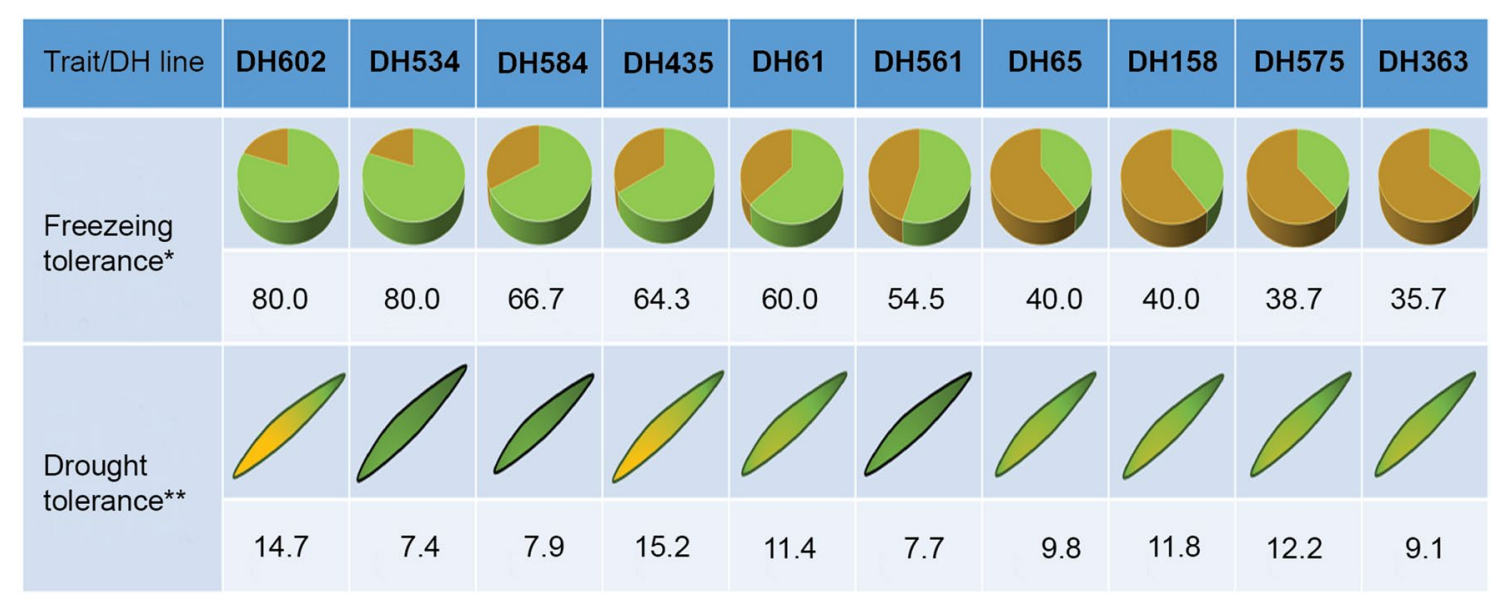

Fig. 1 Freezing and drought tolerance of selected DH lines of winter barley. *Freezing tolerance based on the percentage of plant survival evaluated 3 weeks after laboratory freezing test $\left(8 \mathrm{~h}\right.$ at $\left.-12{ }^{\circ} \mathrm{C}\right)$ according to Rapacz et al. (2011). **Drought tolerance based on the loss of water content (\% of control) in leaves of plants growing for 2 weeks at 35\% soil water content according to Hura et al. (2017). Evaluation of drought tolerance was performed based on leaf water content (LWC) and leaf water loss (LWL) parameters according to the following equations: $\mathrm{LWC}=\left(\left(\mathrm{L}_{\mathrm{FM}}-\mathrm{L}_{\mathrm{DM}}\right) / \mathrm{L}_{\mathrm{FM}}\right) \times 100 \%$, $\mathrm{LWL}=\left[\left(\mathrm{LWC}_{\mathrm{C}}-\mathrm{LWC}_{\mathrm{DT}}\right) / \mathrm{LWC}_{\mathrm{C}}\right] \times 100 \%$, where $\mathrm{L}_{\mathrm{FM}}$ is leaf fresh mass, $\mathrm{L}_{\mathrm{DM}}$ is leaf dry mass after 72 -h lyophilization, $\mathrm{LWC}_{\mathrm{C}}$ is leaf water content of control plants, $\mathrm{LWC}_{\mathrm{DT}}$ is leaf water content of drought-treated plants 
photoperiod and irradiance of $400 \mu \mathrm{mol} \mathrm{m}^{-2} \mathrm{~s}^{-1}$ (HPS lamps, SON-T + AGRO, Philips, Brussels, Belgium). At the stage of three leaves, the seedlings [stage 13 according to Biologische Bundesantalt, Bundessortenamt and Chemische Industrie (BBCH) scale] were transferred to a fully controlled chamber for cold hardening [20 days at $4 / 2{ }^{\circ} \mathrm{C}$ (day/night), photoperiod $9 / 15 \mathrm{~h}$, irradiance of $250 \mu \mathrm{mol} \mathrm{m}^{-2} \mathrm{~s}^{-1}$, SON-T + AGRO] according to the method described by Rapacz et al. (2008, 2010).

As plants acquire their freezing tolerance during cold acclimation, at low though non-freezing temperatures, all analyses were conducted first in seedlings at 3-leaf stage of development growing under physiologically optimal temperature regime (control), then in seedlings after 20-day cold hardening at $4 / 2{ }^{\circ} \mathrm{C}$ (day/night).

The experimental design was completely randomized. Samples - the whole above-ground parts of seedlingswere collected before (control) and after cold hardening period (cold hardened seedlings). The above-ground parts of six seedlings were considered as one biological replicate. The exception was analysis of BRs, where only the middle part of the best developed leaf of one seedling per sample was collected. The studied parameters were measured in three to four biological replicates. The scheme of the experiment is presented on Fig. 2.

\section{Experiment 2. Conditions of plant growth, drought treatment and sampling}

The plants were grown in plastic pots $\left(3.7 \mathrm{dm}^{3}\right.$ in volume, 6 plants per pot), filled with a homogeneous mixture of soil and sand $(1: 1, \mathrm{v} / \mathrm{v})$ in a greenhouse chamber at $25-30 / 18^{\circ} \mathrm{C}$ $\left( \pm 2{ }^{\circ} \mathrm{C}\right)$ day/night and relative air humidity ca. $40 \%$. Plants were illuminated at PPFD of $150-200 \mu \mathrm{mol} \mathrm{m}^{-2} \mathrm{~s}^{-1}$ provided by high pressure sodium lamps (Philips SON-T AGRO, Brussels, Belgium).

Soil drought was applied individually to plants of each DH line at the generative stage of development with fully developed flag leaf (stage 47 according to $\mathrm{BBCH}$ scale). Water content in the pots was gradually reduced to $35 \%$ soil water content (SWC) in relation to maximum water holding capacity of soil and sand mixture, by not watering the plants for 1 week, and was maintained at that level for the next 2 weeks. Control plants were grown in the pots with water content adjusted to $75 \%$. Soil water content was set daily between 9:00 and 11:00 a.m. with the use of the gravimetric method according to Hura et al. (2017). Both control and drought-treated plants were grown at relative humidity ca. $45 \%$. The effects of drought were analysed at the end of the drought period.

The experimental design was completely randomized. The leaf samples (the second leaf below the flag leaf) were harvested, frozen in liquid nitrogen, and stored at $-80{ }^{\circ} \mathrm{C}$. The leaves from three plants were considered as one biological replicate. The exception was analysis of BRs, where only the middle part of one leaf per sample was collected. The studied parameters were measured in three to four biological replicates. The scheme of the experiment is presented on Fig. 2.

\section{Experiment 1}

$10 \mathrm{DH}$ lines of winter barley:

Freezing tolerant $(T)$

Moderately tolerant (MT)

Freezing sensitive (S)

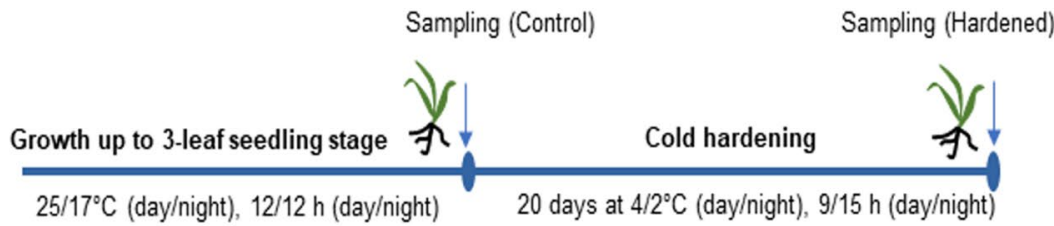

\section{Experiment 2}

$10 \mathrm{DH}$ lines of winter barley:

Drought tolerant (T)

Moderately tolerant (MT)

Drought sensitive (S)

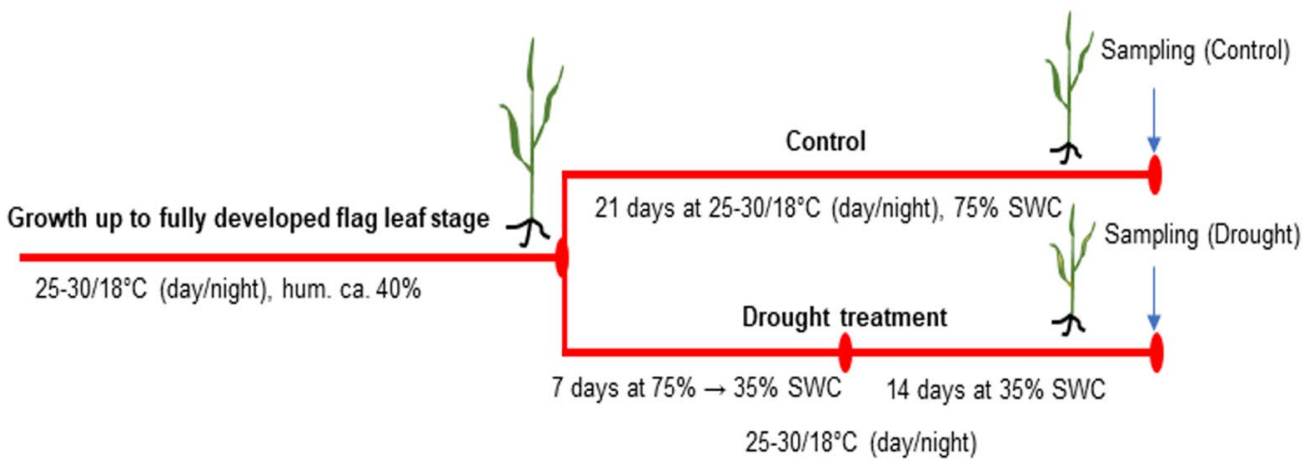

Fig. 2 The scheme of the experiments for the detection of brassinosteroids, salicylic and abscisic acids involvement in the regulation of drought and freezing tolerance 


\section{Measurements of abscisic acid (ABA)}

In preparation for $\mathrm{ABA}$ measurements, samples of barley leaves were freeze-dried and ground with ball mill MM400 (Retsch, Haan, Germany) in Eppendorf vials. After adding $1.5 \mathrm{ml}$ of cold distilled water, the vials were heated for $3 \mathrm{~min}$ in thermoblock set to $90{ }^{\circ} \mathrm{C}$ and then shaken overnight at $4{ }^{\circ} \mathrm{C}$ in order to extract ABA (Quarrie et al. 1988). The next day, the aqueous extracts were centrifuged for $20 \mathrm{~min}$ in a refrigerated centrifuge at $18,000 \times g(\mathrm{MPW}-350 \mathrm{R}$, Warsaw, Poland). ABA was measured in the supernatant using indirect enzyme-linked immunosorbent assay (ELISA) according to Walker-Simmons and Abrams (1991) with modifications by Żur et al. (2015), using the antibody MAC 252 (Babraham Technix, Cambridge, UK).

\section{Measurements of salicylic acid (SA)}

The procedure of SA measurements was based on the protocol of Moravcova et al. (2018). Firstly, barley leaves were collected and promptly frozen in liquid nitrogen $\left(\mathrm{N}_{2}\right)$. Samples were homogenized and extracted with cold methanol, supplemented with internal standard of [3,4,5,6-2H4]-salicylic acid (D4SA), then sonicated and centrifuged. The supernatant was collected and purified with Oasis MCX SPE columns (Waters, Milford, MA, USA). Analytical samples were analyzed with the UHPLC system Agilent 1260 connected to the 6420 ESI Tandem Mass spectrometer with the column Supelco Ascentis RP-Amide $(7.5 \mathrm{~cm} \times 4.6 \mathrm{~mm}$, $2.7 \mu \mathrm{m})$. Gradient UHPLC analyses of $0.1 \%$ formic acid in water and acetonitrile under a flow rate of $0.5 \mathrm{ml} \mathrm{min}^{-1}$ were performed. Two most abundant secondary ions (MRMs) were chosen for the identification and quantification of SA (primary ion 139.0, secondary ions 121.0 and 39.0) and D4SA (primary ion 143.1, secondary ions 125.1 and 41.1). Ten-point calibration curves were prepared for the analyzed compounds.

\section{Measurements of brassinosteroids (BRs)}

The analysis of BRs was performed according to modified protocol by Oklestkova et al. (2017). Firstly, the leaves (0.03-0.3 g FW) were powdered in liquid $\mathrm{N}_{2}$ and after extraction in ice-cold $80 \%$ methanol, centrifuged. Supernatant was supplemented with internal standards of deuterium labelled BR mix. Samples were passed through Discovery columns (Supelco, Bellefonte, PA, USA), evaporated under $\mathrm{N}_{2}$, reconstructed up to $1 \mathrm{ml}$ volume and then passed through immunoaffinity columns (Laboratory of Growth Regulation, Olomouc, Czech Republic). BRs were then eluted from columns using cold $100 \%$ methanol. After evaporation to dryness, samples were again reconstructed in small amounts of methanol. BRs were analyzed with liquid chromatography with tandem mass spectrometry (UHPLC-MS/MS) [an ACQUITY UPLC I-Class System (Waters, Milford, MA, USA) with the use of triple quadrupole mass spectrometer Xevo TQ-S MS (Waters MS Technologies, Manchester, UK)]. Details for conditions of UHPLC-MS/MS analysis are described by Oklestkova et al. (2017).

\section{Statistical analysis}

The evaluation of data started with descriptive statistical analysis (mean, standard error). Then, the variables were examined by analysis of variance (ANOVA) and post hoc comparison with Duncan's multiple range test $(\mathrm{p} \leq 0.05)$. Nonparametric Spearman's rank-order correlation coefficient (R) was used to visualize parameters significantly related to the level of stress tolerance and to detect relations between mean antioxidative activity and mean phytohormone levels. All statistical analyses were performed using STATISTICA version 12.0 (Stat Soft, Inc., USA) package.

\section{Results}

\section{Phytohormone profiles in barley seedlings and their changes induced in response to low temperature hardening treatment}

The content of ABA in barley seedlings ranged from 116 to $276 \mathrm{pmol} \mathrm{g}^{-1} \mathrm{FW}$ (Fig. 3a) and was significantly influenced by the plant genotype. Significant variation between DH lines characterized by different freezing tolerance was also observed (Table 1). Significantly lower level of ABA detected in control seedlings of freezing tolerant DH lines was confirmed by negative correlation $(R=-0.88$ at $\mathrm{p} \leq 0.05$ ) revealed between the level of freezing tolerance and ABA content. In the majority of the studied DH lines of barley, cold hardening did not induce any significant effect on ABA level at the end of this process (Fig. 3a; Table 1). Exceptionally, higher/lower level of ABA was detected in hardened seedlings of DH534/DH158. Negative correlation $(\mathrm{R}=-0.63$ at $\mathrm{p} \leq 0.05)$ between $\mathrm{ABA}$ and freezing tolerance was detected also in seedlings after cold hardening.

In contrast, highly differentiated, genotype-dependent level of SA was detected in control seedlings of the studied DH lines of barley (5-28 pmol g ${ }^{-1}$ FW, Fig. 3b). Higher level of SA seems to be associated with higher freezing tolerance (Table 1) though this effect is the result of uniquely high SA content detected in seedlings of one of two most freezing tolerant DH lines (DH534). In the majority of the studied DH lines (with the exception of DH65), cold hardening resulted in restricted SA accumulation (Fig. 3b), which resulted in a decrease of SA content from mean value of 13 to $6 \mathrm{pmol} \mathrm{g}^{-1} \mathrm{FW}$. But only in the groups of moderately 
Fig. 3 The content of phytohormones in the seedlings of $10 \mathrm{DH}$ lines of winter barley at 3-leaf stage of development and changes in their accumulation induced by cold hardening [20 days at $4 / 2{ }^{\circ} \mathrm{C}$ (day/night)]. The data are the means $( \pm \mathrm{Se})$ from three to four biological replicates. Analysis of variance (ANOVA) was made separately for each tested parameter.

Values marked with the same letter do not differ significantly according to the Duncan test $(\mathrm{p} \leq 0.05)$. a Abscisic acid (ABA). b Salicylic acid (SA). c Homocastasterone (HCS)
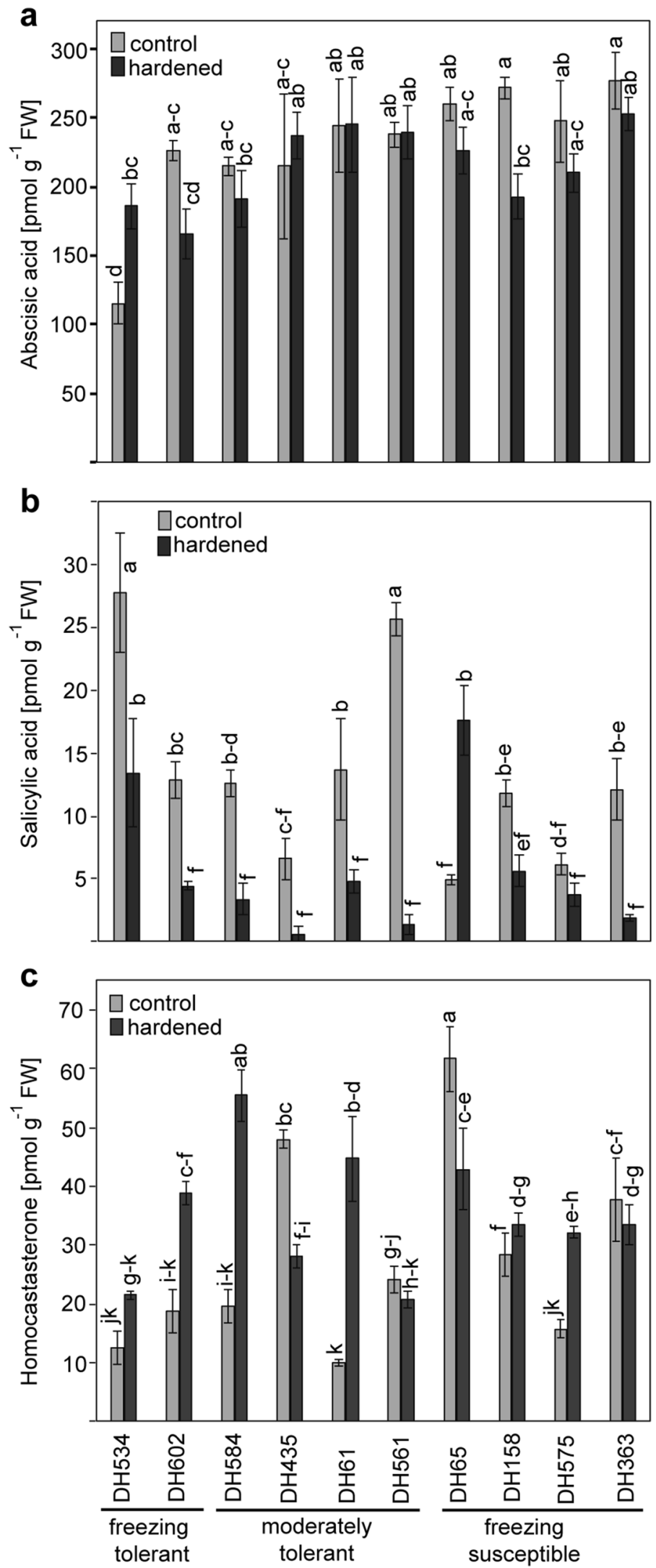
Table 1 The content of abscisic acid (ABA), salicylic acid (SA) and homocastasterone (HCS) in DH lines of winter barley significantly differentiated in respect of freezing tolerance level

\begin{tabular}{lllrl}
\hline Treatment & $\begin{array}{l}\text { Freezing } \\
\text { tolerance }\end{array}$ & ABA & \multicolumn{1}{l}{ SA } & HCS \\
\hline Control & $\mathrm{S}$ & $246 \pm 172^{\mathrm{a}}$ & $8.7 \pm 0.2^{\mathrm{bc}}$ & $35.9 \pm 5.5^{\mathrm{a}}$ \\
& $\mathrm{MT}$ & $230 \pm 11^{\mathrm{a}}$ & $14.6 \pm 0.3^{\mathrm{ab}}$ & $25.4 \pm 4.3^{\mathrm{ab}}$ \\
& $\mathrm{T}$ & $\mathbf{1 7 1}^{\mathrm{b} \mathbf{2 0}^{\mathbf{b}}}$ & $\mathbf{2 0 . 3} \pm \mathbf{0 . 7}^{\mathrm{a}}$ & $\mathbf{1 5 . 7} \pm \mathbf{2 . 5}^{\mathbf{b}}$ \\
Cold-hardened & $\mathrm{S}$ & $219 \pm 8^{\mathrm{a}}$ & $7.2 \pm 0.3^{\mathrm{c}}$ & $35.5 \pm 2.1^{\mathrm{a}}$ \\
& $\mathrm{MT}$ & $231 \pm 13^{\mathrm{a}}$ & $2.5 \pm 0.1^{\mathrm{c}}$ & $37.2 \pm 4.5^{\mathrm{a}}$ \\
& $\mathrm{T}$ & $\mathbf{1 7 8}^{\mathbf{1 7 2}}$ & $8.9 \pm 0.5^{\mathrm{bc}}$ & $30.2 \pm 4.0^{\mathrm{a}}$ \\
\hline
\end{tabular}

The content of phytohormones $\left(\mathrm{pmolg}^{-1} \mathrm{FW}\right.$ ) was measured in the whole above-ground parts of seedlings growing at $25 / 17{ }^{\circ} \mathrm{C}$ (day/ night) (control) and then after the process of cold hardening [20 days at $4 / 2{ }^{\circ} \mathrm{C}$ (day/night)]. The data represent the means from three replicates $\pm \mathrm{Se}$. Values marked with the same letter do not differ significantly according to the Duncan test $(\mathrm{p} \leq 0.05)$. Significant differences between extremes (freezing sensitive and freezing tolerant) DH lines marked in bold. DH lines of barley (a) freezing sensitive (S): DH65, DH158, DH575, DH363, (b) moderately tolerant (MT): DH561, DH61, DH435, DH584, (c) freezing tolerant (T): DH602, DH534

tolerant and freezing tolerant DH lines was this effect statistically significant (Table 1).

Only one BR—homocastasterone (HCS)—was detected in barley seedlings at 3-leaf stage of development (Fig. 3c). Its content in control seedlings varied significantly from 10 to $62 \mathrm{pmol} \mathrm{g}^{-1} \mathrm{FW}$ and was considerably lower in the group of freezing tolerant DH lines (Table 1). Moreover, only in this group cold hardening had a significant effect on HCS accumulation, increasing it approximately 2 -fold, to the value characteristic for two other groups (Table 1).

\section{Phytohormone profiles in barley plants at generative stage and their changes induced in response to drought treatment}

Control plants of all studied DH lines optimally watered during the heading phase of development showed no variation in the content of ABA, detected at relatively low level, from ca. 0.2 to $0.5 \mathrm{nmol} \mathrm{g}^{-1} \mathrm{FW}$ (Fig. 4a). Drought treatment resulted in a dramatic increase (up to above 12-times) in the content of this compound, with a genotype-dependent amplitude of changes. As a result, in drought-treated plants ABA accumulation ranged from 2 to $7 \mathrm{nmol} \mathrm{g}^{-1} \mathrm{FW}$ and was associated with drought tolerance level (Table 2). Excluding two outliers (DH575 and DH602), significant correlation $(\mathrm{R}=0.83$ at $\mathrm{p} \leq 0.05)$ between ABA content and LWL parameter under water deficiency was revealed.

In contrast, the studied DH lines of barley varied significantly in respect of SA content, which ranged from 14 to $180 \mathrm{pmol} \mathrm{g}^{-1} \mathrm{FW}$ in leaves of heading plants growing at optimal water conditions (Fig. 4b). It could also be noticed that in the majority of moderately tolerant and drought sensitive DH lines water deficit had no influence on SA accumulation, whereas a drastic reduction (from 75 to $84 \%$ ) in the content of this compound was detected in two among three drought tolerant DH lines (Fig. 4b). The elimination of the same two outliers (DH575 and DH602) resulted in a strong correlation $(\mathrm{R}=0.95$ at $\mathrm{p} \leq 0.05)$ between SA content and LWL parameter (corresponding to drought sensitivity) in plants growing under water deficit.

Four BRs were detected in leaves of plants of the studied DH barley lines at generative phase of development (Fig. 4c-f). Among them, HCS was detected in the highest proportion of ca. $94.7 \%$ of total BR content, with only minor representation of castasterone (CS, ca. 4.0\%), teasterone (TE, ca. $1.1 \%$ ) and dolicholide (DL, ca. $0.2 \%)$. The last one was for the first time detected in any cereal species. Almost the same proportion of BRs was revealed in plants after drought treatment, where HCS, CS, TE and DL represented $95.3 \%, 3.7 \%, 0.85 \%$ and $0.2 \%$ of total BRs pool, respectively. Both optimally irrigated and drought-treated plants of all studied DH lines varied significantly in respect of HCS, CS and DL accumulation (ANOVA, $p \leq 0.05$ ), whereas constitutive level of TE was very similar in all studied plants and not influenced by drought treatment. Control plants of barley characterized by different drought tolerance level varied only in respect of CS, accumulated at higher concentration in drought sensitive DH lines (Table 2), although this effect was influenced mainly by its significantly higher level in only one genotype (DH602). The effects of soil water deficiency on BR accumulation were associated with the level of drought tolerance (Table 2). Only drought sensitive DH lines responded with significantly enhanced accumulation of about $27 \%, 41 \%$ and $50 \%$ for TE, HCS and DL, respectively (Fig. 4c, e, f; Table 2). In contrast, only in DH lines with the highest drought tolerance, a significant, almost 2-fold increase in the content of CS was observed (Table 2).

\section{Discussion}

Barley is one of the first domesticated plant species which has been intensively bred with improved performance and malting quality as the most important targets. Due to genetic drift and long-term inbreeding, modern barley cultivars are characterized by narrowed genetic diversity in comparison with their wild ancestors (Caldwell et al. 2006), especially in the case of genes involved in environmental adaptation ability (Schmid et al. 2018). As a result, two main threats connected with winter barley cultivation are: low freezing 

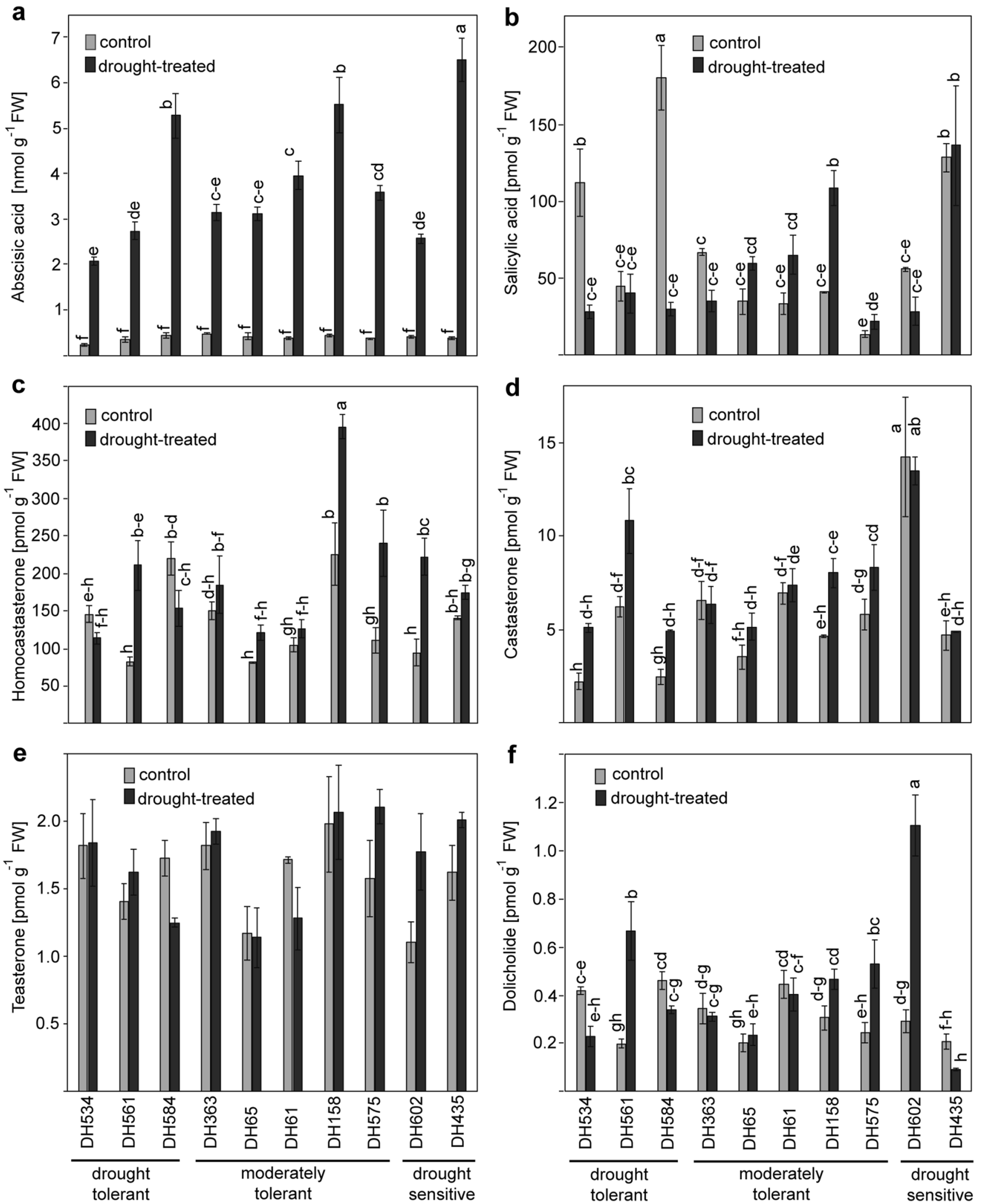

Fig. 4 The content of phytohormones in leaves of $10 \mathrm{DH}$ lines of winter barley at heading stage of development growing at $75 \%$ soil water content (control) and their changes induced in response to drought treatment ( 2 weeks at $35 \%$ soil water content). The data are the means $( \pm \mathrm{Se})$ from three to four biological replicates. Analysis of

variance (ANOVA) was made separately for each tested parameter. Values marked with the same letter do not differ significantly according to the Duncan test $(\mathrm{p} \leq 0.05)$. a Abscisic acid (ABA). b Salicylic acid (SA). c Homocastasterone (HCS). d Castasterone (CS). e Teasterone (TE). f Dolicholide (DL) 
Table 2 The content of abscisic acid (ABA), salicylic acid (SA) and brassinosteroids: homocastasterone (HCS), castasterone (CS), teasterone (TE) and dolicholide (DL) in DH lines of winter barley significantly differentiated in respect of drought tolerance

\begin{tabular}{|c|c|c|c|c|c|c|c|}
\hline Treatment & $\begin{array}{l}\text { Drought toler- } \\
\text { ance }\end{array}$ & ABA & SA & HCS & $\mathrm{CS}$ & $\mathrm{TE}$ & DL \\
\hline \multirow[t]{3}{*}{ Control } & $\mathrm{S}$ & $393 \pm 20^{c}$ & $92.4 \pm 16.7^{\mathrm{ab}}$ & $118 \pm 13^{b}$ & $9.5 \pm 2.6^{\mathrm{a}}$ & $1.4 \pm 0.2^{\mathrm{b}}$ & $0.3 \pm 0.03^{\mathrm{b}}$ \\
\hline & MT & $415 \pm 18^{\mathrm{c}}$ & $38.1 \pm 4.9^{\mathrm{c}}$ & $135 \pm 16^{\mathrm{ab}-}$ & $5.5 \pm 0.4^{\mathrm{bc}}$ & $1.7 \pm 0.1^{\mathrm{ab}}$ & $0.3 \pm 0.03^{\mathrm{b}}$ \\
\hline & $\mathrm{T}$ & $318 \pm 32^{\mathrm{c}}$ & $112.3 \pm 21.6^{\mathrm{a}}$ & $150 \pm 21^{\mathrm{ab}}$ & $3.8 \pm 0.7^{\mathrm{c}}$ & $1.7 \pm 0.1^{\mathrm{ab}}$ & $0.3 \pm 0.04^{\mathrm{b}}$ \\
\hline \multirow[t]{3}{*}{ Drought-treated } & $\mathrm{S}$ & $4316 \pm 519^{a}$ & $82.4 \pm 30.0^{\mathrm{ab}}$ & $199 \pm 16^{\mathrm{a}}$ & $10.1 \pm 2.5^{\mathrm{a}}$ & $1.9 \pm 0.1^{\mathrm{a}}$ & $0.6 \pm 0.2^{\mathrm{a}}$ \\
\hline & MT & $3874 \pm 194^{\mathrm{ab}}$ & $54.6 \pm 8.3^{\mathrm{bc}}$ & $214 \pm 29^{a}$ & $7.0 \pm 0.5^{\mathrm{ab}}$ & $1.7 \pm 0.1^{\mathrm{ab}}$ & $0.4 \pm 0.04^{\mathrm{ab}}$ \\
\hline & $\mathrm{T}$ & $3253 \pm 316^{b}$ & $32.8 \pm 4.5^{c}$ & $159 \pm 19^{a b}$ & $7.0 \pm 1.1^{\mathrm{ab}}$ & $1.6 \pm 0.1^{\mathrm{ab}}$ & $0.4 \pm 0.08^{\mathrm{ab}}$ \\
\hline
\end{tabular}

The content of phytohormones $\left(\mathrm{pmolg}^{-1} \mathrm{FW}\right.$ ) was measured in the leaves of plants at the generative phase of development growing at $75 \%$ soil water content (control) and after 2 weeks growth at $35 \%$ soil water content (drought-treated plants). The data represent the means from three biological replicates \pm Se. Values marked with the same letter do not differ significantly according to the Duncan test $(\mathrm{p} \leq 0.05)$. Significant differences between extremes (drought sensitive vs. drought tolerant) DH lines marked in bold. DH lines of barley (a) drought sensitive (S): DH602, DH435, (b) moderately tolerant (MT): DH363, DH65, DH61, DH158, DH575, (c) drought tolerant (T) DH534, DH561, DH584

tolerance of seedlings and high sensitivity to water scarcity at generative stage of development.

Ten DH lines of winter barley characterized by increased range of variation in stress acclimation ability were used as the model to study the involvement of selected phytohormones in the regulation of plant freezing and drought tolerance. Despite various stress factors, both freezing and drought stresses induce the same physiological effect of plant cell dehydration (Rajashekar 2016). It could be supposed that plants with higher water retention capability, which is probably the result of higher osmolyte accumulation, should be better adapted to both stress factors (Walker et al. 2010). The results of freezing/drought tolerance tests showed however that only one (DH534) among studied DH lines was highly tolerant to both freezing and drought stresses. The whole spectrum of freezing/drought adaptation responses was observed among the rest of studied barley genotypes.

\section{Content of ABA, SA and BRs at various stage of plant development}

The scheme of the present study analysing the effects of cold hardening and drought stress applied at the most critical stages of plant growth, allows us to compare phytohormonal content at vegetative and generative phases of plant development. The level of all studied phytohormones was significantly higher in heading plants in comparison to seedlings: more than 5-fold in respect of mean SA (13 vs. $71 \mathrm{pmolg}^{-1}$ FW) and mean total BRs contents ( 28 vs. 143 pmol g$^{-1} \mathrm{FW}$ ) and 1.7-fold in the case of ABA (224 vs. $386 \mathrm{pmol} \mathrm{g}^{-1} \mathrm{FW}$ ).

The ABA levels received in this study $\left(115-276 \mathrm{pmol} \mathrm{g}^{-1}\right.$ FW equal to $1-2 \mathrm{nmolg}^{-1} \mathrm{DW}$ ) for non-acclimated seedlings correspond to those received by Bravo et al. (1998). However, differences among DH lines were much smaller than those observed among cultivars in the afore-mentioned study, which suggests genetic homogeneity of all DH lines investigated in respect of constitutive endogenous $\mathrm{ABA}$ level. A similar level (c.a. $2 \mathrm{nmol} \mathrm{g}^{-1} \mathrm{DW}$ ) of endogenous ABA was also detected at seedling stage in androgenic forms of Festulolium (Pociecha et al. 2009). The level of ABA measured in optimally watered plants at generative phase of development ranged from 228 to $475 \mathrm{pmol} \mathrm{g}^{-1} \mathrm{FW}$ and showed no significant variation among tested DH lines. Quite similar results were published also by Seiler et al. (2014), who investigated breeding and transgenic barley lines.

In contrast, our study revealed that both seedlings and heading plants of barley growing at control conditions differ significantly with respect to endogenous SA content, detected in the ranges $6-28 \mathrm{pmol} \mathrm{g}^{-1} \mathrm{FW}$ and 14-180 pmol g$^{-1} \mathrm{FW}$, respectively. Such high genotypic variation in SA content among studied DH lines of barley was also observed among androgenic forms of Festulolium (Pociecha et al. 2009). The level of SA seems to be rather low as usual, under optimal environmental conditions-it was detected in the range of $10-100 \mathrm{ng} \mathrm{g}^{-1} \mathrm{FW}$ (review in Janda et al. 2014). However, depending on the plant species and the stage of plant development the level of SA varies in the range of several orders of magnitude. Higher content of SA in plants at generative stage of development is in agreement with earlier published data e.g. SA levels in tobacco and Arabidopsis leaves increased 5-fold at the initiation of flowering (review in Vicente and Plasencia 2011).

The content of HCS detected as the only BR in winter barley seedlings was comparable to that received by Sadura et al. (2019) and Gruszka et al. (2016a) with the use of spring barley varieties. These authors also reported a very low level of two other BRs (brassinolide and CS) detected in three to four leaf seedlings whereas in our study, the spectrum of identified BRs increased in plants entering the generative phase of development. HCS again predominated, 
which is in agreement with earlier studies on barley cultivars and their mutants (Sadura et al. 2019; Gruszka et al. 2016a). Among three other identified BRs, DL was detected for the first time in any cereal species. Earlier studies of Abe et al. (1984) and Gamoh et al. (1990) reported the occurrence of a similar compound - dolichosterone, probable precursor of DL-in rice and maize. The presence of BRs from different structural groups of C27 (TE, CS), C28 (DL) and C29 (HCS) suggests the existence of independent pathways for BR biosynthesis using different sterol precursors or their conversion (Janeczko 2016; Sadura and Janeczko 2018; Joo et al. 2015).

\section{Changes in phytohormone content associated with stress treatment}

A key role in the process of cold acclimation is usually attributed to ABA (Gusta et al. 2005). For example, Bravo et al. (1998) showed that the constitutive ABA level in nonacclimated barley seedlings correlated with freezing tolerance of the cultivars investigated. Moreover, treatment of seedlings with exogenous ABA increased freezing tolerance but only in the cultivar with the lowest constitutive endogenous $\mathrm{ABA}$, indicating that the high endogenous ABA level in non-acclimated seedlings is already the optimum for the induction of freezing tolerance. In our study, not only ABA content was negatively correlated with barley seedlings' freezing tolerance $(\mathrm{R}=-0.63$; Fig. $5 \mathrm{a})$ but, in contrast to the majority of published data (e.g. Sadura et al. 2019), ABA level in almost all studied DH lines of barley was not influenced significantly by cold hardening treatment. Only one of two studied DH lines with the highest freezing tolerance level (DH534) responded in accordance with the expected pattern, increasing ABA accumulation more than 1.5 times. This observation could be explained by some literature data, showing only a transient $\mathrm{ABA}$ increase within the first 12-24 h of cold acclimation of plants, which was followed by a substantial decrease during further acclimation (Murelli et al. 1995). This time-limited acclimation response was sufficient to trigger different fast and/or slow signalling pathway transduction chains. The presented results suggest that ABA involvement in cold hardening and freezing tolerance in barley cannot be explained simply by the pattern of its level changes. A similar conclusion can be found in the paper by Kadlecova et al. (2000). Therefore, only the analysis of the whole hormonal balance during cold hardening of barley plants can reveal the pivotal role of ABA in freezing tolerance.

The involvement of ABA in plant response to drought is one of the best recognized mechanisms of plant acclimation to abiotic stresses. The main role of ABA increase in plants subjected to drought is leaf stomata closure, limiting water loss through transpiration, and an increase in root water conductivity with the aim of improving water uptake and transport from the soil through the roots to the above-ground part of the plant (Zhang et al. 2006). Additionally, ABA induces the expression of many genes enhancing plant tolerance to drought stress (Parent et al. 2009; Zhang et al. 2006; Tommasini et al. 2008). Water deficit in plants quickly induces an increase in ABA level (Popova et al. 1996; Bandurska and Stroinski 2003; Xue and Loveridge 2004). A dramatic, almost 10 -fold increase in ABA content was also observed in this study, in all DH lines of barley. However, again this effect was more pronounced in drought sensitive DH lines, which could be at least partially explained by higher water loss and lower leaf water content detected in these plants in comparison with more tolerant ones (Gołębiowska-Pikania et al. 2017b).

Several studies demonstrated positive effect of exogenous SA application on chilling and drought tolerance in various plant species, including barley and wheat (Mutlu et al. 2013; Esim and Atici 2015). The mechanism of this positive effect is probably based on its signalling function as elevated SA upregulates specific genes whose products are involved in stress response e.g. peroxidase, glutathione S-transferase, dehydrin-like proteins, heat shock proteins, alternative oxidase and superoxide dismutase (SOD). Usually, plants with very low level of SA experience more severe damages under various abiotic stresses (Yuan and Lin 2008). On the other hand, a recent study suggests that only low concentration of SA stimulates antioxidative activity in plants whereas high level of this compound can initiate cell death or higher susceptibility to stress (Jumali et al. 2011). In our study, significantly higher endogenous content of SA in seedlings of freezing tolerant $\mathrm{DH}$ growing at optimal conditions suggests that tolerance to this stress factor could be under control of some constitutive genotype specific traits. However, the most pronounced variation between DH lines of barley extremely different in respect of freezing and drought tolerance level is their response to these stress treatments, where significantly diminished SA accumulation in the leaves was a response specific for DH lines characterized by the highest stress tolerance. Similar results-significantly higher decrease of SA content in cold acclimated plants of freezing tolerant versus freezing susceptible genotypes of androgenic Festuloliumwere reported by Pociecha et al. (2009).

The role of BRs in the process of plant hardening to frost was investigated earlier by Eremina et al. (2016), who revealed that BRs improved freezing tolerance of plants on the basis of a study on Arabidopsis thaliana mutants with impaired BR signalling. The importance of BR signalling for freezing tolerance was also confirmed for barley (Sadura et al. 2019) as barley BR signalling mutants had lower freezing tolerance than the wild type. The results for BR biosynthesis mutants confirmed it partially, while a disturbance of early stages of biosynthesis resulted in lowered 
Fig. 5 Summary. The effect of cold hardening (a) and drought treatment (b) on the pattern of changes in phytohormone content and their homeostasis, variation in the level of phytohormones detected in $\mathrm{DH}$ lines extremely differentiated in respect of freezing/drought tolerance level and the correlation between the level of phytohormones, stress tolerance and the activity of nonspecific peroxidase (POX) and low molecular weight antioxidants (LMW AOX). Arrows indicate the predominant direction of changes in the level of phytohormones and their homeostasis: increase $(\uparrow)$, decrease $(\downarrow)$ or constant $(=)$ in stress sensitive $(\mathrm{S})$, moderately tolerant (MT) and stress tolerant (T) DH lines of winter barley. Variation of extremes is presented in colour according to an arbitrarily adopted scale corresponding to the results of the Duncan's multiple range test $(\mathrm{p} \leq 0.05)$. Correlation coefficient $(\mathrm{R})$ was estimated by nonparametric Spearman's rankorder. ${ }^{a}$ Correlation significant after elimination of two outliers. $A B A$ abscisic acid, $S A$ salicylic acid, HCS homocastasterone, $C S$ castasterone, $T E$ teasterone, $D L$ dolicholide, $S c$ control seedlings/heading plants sensitive to freezing/drought treatment, $T c$ control seedlings/heading plants tolerant to freezing/drought treatment, $S_{H}$ cold hardened seedlings sensitive to freezing stress, $T_{H}$ cold hardened seedlings tolerant to freezing stress, $S_{D}$ drought treated plants sensitive to drought stress, $T_{D}$ drought treated plants tolerant to drought stress

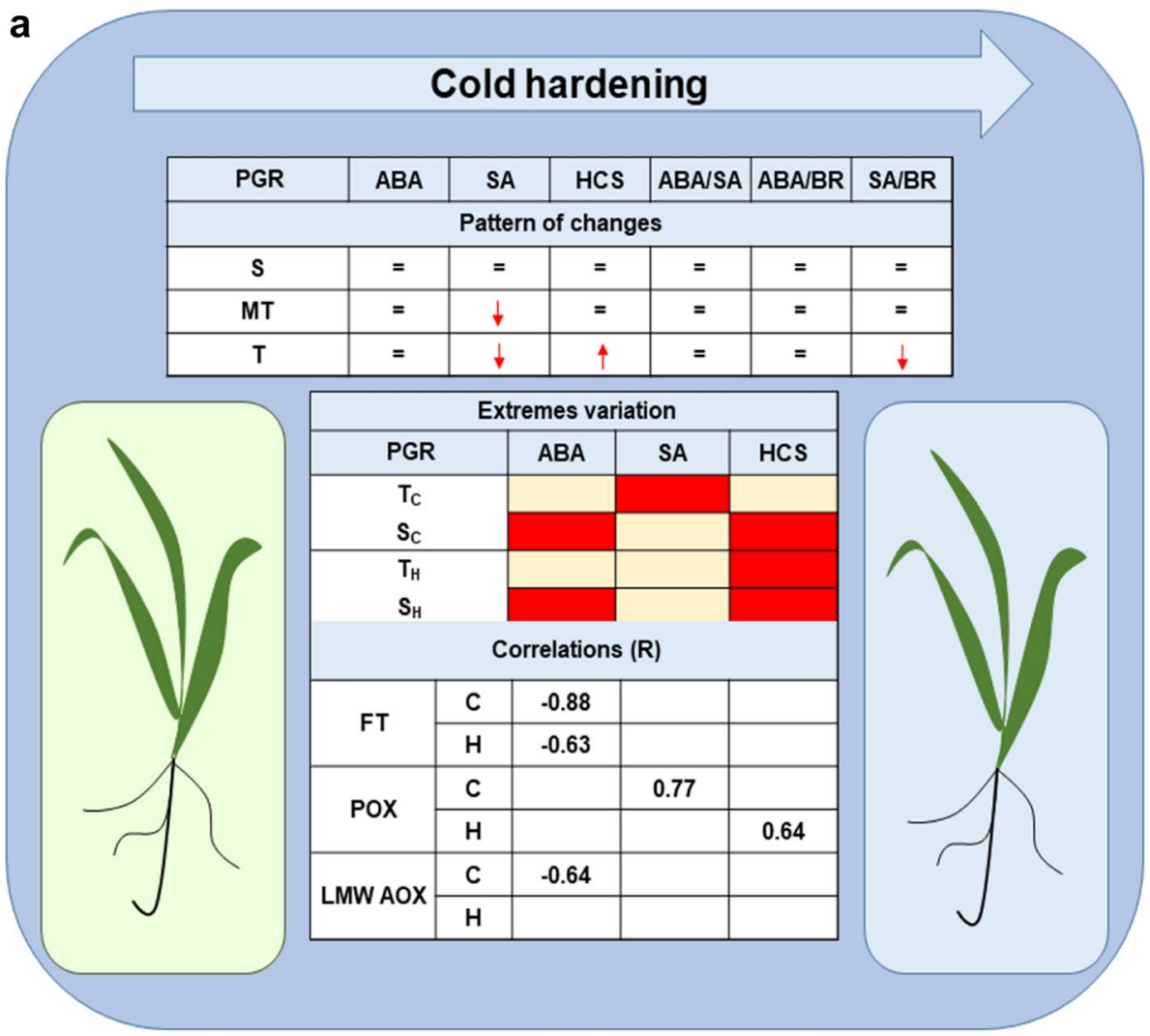

b

\section{Drought treatment}

\begin{tabular}{|c|c|c|c|c|c|c|c|c|c|}
\hline PGR & ABA & SA & HCS & CS & TE & DL & ABA/SA & ABA/BR & SA/BR \\
\hline \multicolumn{10}{|c|}{ Patern of changes } \\
\hline S & $\uparrow$ & $=$ & $\uparrow$ & $=$ & $\uparrow$ & $\uparrow$ & $=$ & $\uparrow$ & $=$ \\
\hline MT & $\uparrow$ & $=$ & $=$ & $=$ & $=$ & $=$ & $\uparrow$ & $\uparrow$ & $=$ \\
\hline T & $\uparrow$ & $\downarrow$ & $=$ & $\uparrow$ & $=$ & $=$ & $\uparrow$ & $\uparrow$ & $\downarrow$ \\
\hline
\end{tabular}

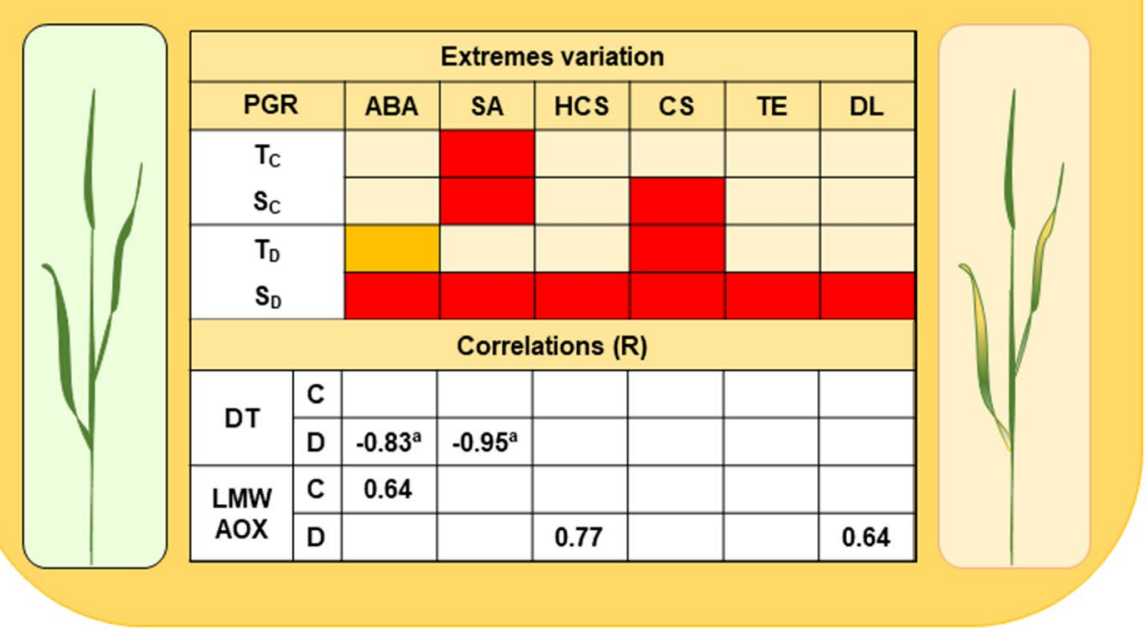


freezing tolerance, whereas disturbances in later stages of BR biosynthesis had no effect. According to literature, the content of BRs increased in cold hardened winter rye (Pociecha et al. 2016) and spring barley (Sadura et al. 2019), which is to some extent in accordance with data obtained in this study as significant increase in HCS content was noted for more freezing tolerant DH lines of barley. Previous studies with spring barley (Sadura et al. 2019) and winter wheat (Janeczko et al. 2019) also showed that cultivars less tolerant to freezing accumulated lower amounts of BRs (especially HCS) in response to cold hardening in comparison with more tolerant cultivars. These results suggest that although the final content of HCS measured in cold hardened seedlings cannot be used as the marker of freezing tolerance in barley, such role could be played by the amplitude of changes induced by the process of hardening. The dramatic increase in HCS content specific only for freezing tolerant DH lines of barley also suggests its direct involvement in freezing tolerance acquisition.

The consistent increase in BR accumulation observed in response to drought stress is in agreement with earlier studies on barley and its BR signaling and BR-deficient mutants (Gruszka et al. 2016b). However, whereas increased level of HCS and DL observed in our study in leaves of drought sensitive DH lines could be used as the low tolerance marker, significantly increased content of CS specific only for drought tolerant $\mathrm{DH}$ lines suggests its role in plant acclimation to water scarcity. Similarly, Gruszka et al. (2016a, b) proposed CS as the suggested end product of the BR biosynthetic pathway in monocots to be drought-induced compound. For some plant species e.g. tobacco, rice or pea, it is the main biologically active BRs (Reid et al. 2010).

It is well known that the content and profile of BRs may be modified significantly by environmental factors. Exogenous BR application on drought stressed plants and low temperature treated plants was beneficial, improving stress tolerance and resulting in higher yield production (Bajguz and Hayat 2009; Sadura and Janeczko 2018). It is connected to BR-induced increase in chlorophyll contents and photosynthetic capacity which determines biomass accumulation. BRs also stimulate accumulation of anti-stress agents e.g. proline, counteracting negative effects of various kind of stresses. They enhance antioxidant system capacity, increasing enzymatic activity and upregulating stress response genes, among others the ones encoding SOD, catalase (CAT) and peroxidases (review in Anwar et al. 2018).

\section{Changes in hormone homeostasis induced by cold hardening and drought treatments}

Plant hormones are the key factors regulating plant growth, development and stress acclimation. However, they act in a very complex network interacting at the level of biosynthesis, distribution, gene expression or signalling. Thus, not only the changes in the level of phytohormones per se but disturbances in their homeostasis are essential for stress response (Verma et al. 2016).

In the present study, hardening and drought treatments coincided with both common and specific disturbances in phytohormone content and their homeostasis necessary to induce signal transduction and plant stress acclimation. Summarizing all observed changes, it could be seen that both cold hardening and drought induced significant changes in SA/BR ratio, increasing BR predominance in DH lines of barley with higher stress tolerance (Fig. 5a, b). Dramatically enhanced ABA accumulation induced by soil water deficit increased its content in comparison with BRs in all studied DH lines of barley, whereas a significant increase in ABA/ SA was observed only in more drought tolerant genotypes (Fig. 5b).

\section{Correlation analysis among stress tolerance level, phytohormone content and activity of the antioxidative system}

Among various parameters identified in our previous studies (Gołębiowska-Pikania et al. 2017a), the most important role in tolerance to freezing and limited water availability seems to be played by effective antioxidative defence (Gołębiowska-Pikania et al. 2017b). As the majority of phytohormones are involved in the regulation of antioxidative system activity the level of ABA, SA and BRs was correlated with the activities of antioxidative enzymes-SOD, CAT and nonspecific peroxidases (POX) - as well as with the activity of low molecular weight antioxidants (LMW AOX) measured simultaneously and published earlier by Gołębiowska-Pikania et al. (2017a, b).

The analysis confirmed our observations showing negative correlation between the content of ABA and freezing/ drought stress tolerance (Fig. 5a, b). Higher accumulation of this phytohormone seems to be the marker of lower acclimation ability to cold and drought treatment. Interestingly, higher accumulation of ABA was correlated with lower activity of LMW AOX in control seedlings at 3-leaf stage of development and with higher activity of LMW AOX in control generative plants with fully developed flag leaf. This effect could be connected with various endogenous levels of ABA detected at various stages of plant development and some genotype-specific threshold level of ABA necessary for the positive interaction initiation.

Tasgin et al. (2003) reported that exogenous SA application enhanced freezing tolerance of wheat, which resulted from increased activities of antioxidative enzymes and antifreeze proteins. Similar data showing that exogenous treatment with low concentration of SA can increase antioxidative activity were presented by Ananieva et al. (2004). 
Although in our study, endogenous level of SA was not significantly correlated with freezing tolerance, the mechanism of SA action through enhanced antioxidative defence seems to be confirmed by significant correlation detected between its endogenous content and POX activity (Fig. 5a). Similarly to ABA, accumulation of SA was negatively correlated with drought tolerance (Fig. 5b), which confirms earlier reports of dose-dependent SA effects (Jumali et al. 2011).

In response to both stress factors, more intense accumulation of BRs was correlated with higher activity of LMW AOX (Fig. 5a, b). It correspond with the data of Li et al. (2016) showing that exogenous application of BR activates the expression of cellular redox homeostasis-related genes, including GSTX1 (probable glutathione S-transferase). The encoded enzyme regulates conjugation of reduced glutathione (the most abundant cellular LMW AOX) to various substrates for cell detoxification.

In conclusion, some common and specific effects on hormonal content and homeostasis were detected in winter barley plants under cold hardening and drought treatment (Fig. 5a, b). To some extent freezing tolerance seems to be determined by native hormonal status of seedlings, which was not observed in plants at generative stage of development. ABA seems to be involved only in drought stress defence, though its role in fast, cold induced defence reactions cannot be excluded. Significantly lower accumulation of ABA detected in freezing/drought tolerant DH lines under stress treatment probably reflected lower stress intensity, which was suggested by lower level of cell dehydration. In contrast, increased content of some BRs and decreased level of SA resulting in disturbed SA/BRs homeostasis specific for tolerant $\mathrm{DH}$ lines of barley suggest direct involvement of these molecules in the metabolic network responsible for stress defence. Some inconsistency between our study and other published data could be the result of a relatively high number of tested genotypes, which made it possible to reveal huge diversity and complexity of the mechanisms induced in response to low temperature and drought. While drawing conclusions and describing various cold/drought stress response patterns, we should also be aware that to some extent the observed variation could result from different stages of plant development and that further, more precise studies should be performed to discover the actual cause and effect relationships and identify the mechanisms of plant tolerance.

Acknowledgements The research was performed in the frame of the Project HOR.hn.802.15.2018, No. 26 financed by the Polish Ministry of Agriculture and Rural Development within the Program 'Basic Research for Biological Progress in Plant Production'. The analysis of BRs was supported from the European Regional Development Funding Project 'Plants as a Tool for Sustainable Global Development' (No. CZ.02.1.01/0.0/0.0/16 019/0000827). The authors would like to thank Ondřej Novák for help with BRs LC-MS/MS measurement.
Author Contributions IŻ conceived and designed the research, conducted experiments and contribute to the final manuscript. SM conducted experiments and wrote the manuscript. AJ and JO measured BRs content. FJ and KK measured ABA content and activity of LMW AOX. PW measured SA content. ES measured activity of antioxidative enzymes. MR and MW-J tested freezing tolerance. TH, PK and AO tested drought tolerance level. ED, MK and AN conducted experiments and prepared graphical presentation of the results. The corresponding author certifies that all authors have seen and approved the final version of the manuscript being submitted and warrant that the article is the authors' original work, has not received prior publication and is not under consideration for publication elsewhere.

\section{Compliance with ethical standards}

Conflict of interest All authors of this manuscript declare that they have no conflict of interest.

Open Access This article is distributed under the terms of the Creative Commons Attribution 4.0 International License (http://creativeco mmons.org/licenses/by/4.0/), which permits unrestricted use, distribution, and reproduction in any medium, provided you give appropriate credit to the original author(s) and the source, provide a link to the Creative Commons license, and indicate if changes were made.

\section{References}

Abe H, Nakamura K, Morishita T, Uchiyama M, Takatsuto S, Ikekawa N (1984) Endogenous brassinosteroids of the rice plant-castasterone and dolichosterone. Agric Biol Chem Tokyo 48(4):11031104. https://doi.org/10.1080/00021369.1984.10866278

Ananieva EA, Christov KN, Popova LP (2004) Exogenous treatment with salicylic acid leads to increased antioxidant capacity in leaves of barley plants exposed to Paraquat. J Plant Physiol 161(3):319 328. https://doi.org/10.1078/0176-1617-01022

Anwar A, Liu YM, Dong RR, Bai LQ, Yu XC, Li YS (2018) The physiological and molecular mechanism of brassinosteroid in response to stress: a review. Biol Res. 51:46. https://doi.org/10.1186/s4065 9-018-0195-2

Bajguz A (2007) Metabolism of brassinosteroids in plants. Plant Physiol Biochem 45(2):95-107. https://doi.org/10.1016/j.plaph y.2007.01.002

Bajguz A, Hayat S (2009) Effects of brassinosteroids on the plant responses to environmental stresses. Plant Physiol Biochem 47(1):1-8. https://doi.org/10.1016/j.plaphy.2008.10.002

Bandurska H, Stroinski A (2003) ABA and proline accumulation in leaves and roots of wild (Hordeum spontaneum) and cultivated (Hordeum vulgare 'Maresi') barley genotypes under water deficit conditions. Acta Physiol Plant 25(1):55-61. https://doi. org/10.1007/s11738-003-0036-X

Bravo LA, Zuniga GE, Alberdi M, Corcuera LJ (1998) The role of ABA in freezing tolerance and cold acclimation in barley. Physiol Plant 103(1):17-23

Busconi M, Bosco CD, Crosatti C, Baldi P, Mare C, Grossi M, Mastrangelo AM, Rizza F, Cattivelli L, Stanca AM (2001) The coldregulated genes are involved in the physiological response of barley to cold environment. ICL Agric Sci 14:17-27

Caldwell KS, Russell J, Langridge P, Powell W (2006) Extreme population-dependent linkage disequilibrium detected in an inbreeding plant species, Hordeum vulgare. Genetics 172(1):557-567. https ://doi.org/10.1534/genetics.104.038489 
Ceccarelli S, Grando S, Maatougui M, Michael M, Slash M, Haghparast R, Rahmanian M, Taheri A, Al-Yassin A, Benbelkacem A, Labdi M, Mimoun H, Nachit M (2010) Plant breeding and climate changes. J Agric Sci 148:627-637. https://doi.org/10.1017/s0021 859610000651

Cistue L, Valles MP, Echavarri B, Sanz JM, Castillo A (2003) Barley anther culture. In: Maluszynski M, Kasha KJ, Forster BP, Szarejko I (eds) Doubled haploid production in crop plants: a manual. Springer, New York, pp 29-34

Deveraj VR, Dsouza M (2018) Signaling molecules and their involvement in abiotic and biotic stress response crosstalk in plants. In: Ramakrishna A, Gill SS (eds) Metabolic adaptation in plants during abiotic stress. CRC Press, Boca Raton, pp 295-310

Dhabhar FS (2018) The short-term stress response-mother nature's mechanism for enhancing protection and performance under conditions of threat, challenge, and opportunity. Front Neuroendocrinol 49:175-192. https://doi.org/10.1016/j.yfrne.2018.03.004

Eremina M, Unterholzner SJ, Rathnayake AI, Castellanos M, Khan M, Kugler KG, May ST, Mayer KFX, Rozhon W, Poppenberger B (2016) Brassinosteroids participate in the control of basal and acquired freezing tolerance of plants. Proc Natl Acad Sci USA 113(40):E5982-E5991. https://doi.org/10.1073/pnas.1611477113

Esim N, Atici O (2015) Effects of exogenous nitric oxide and salicylic acid on chilling-induced oxidative stress in wheat (Triticum aestivum). Front Life Sci 8(2):124-130. https://doi.org/10.1080/21553 769.2014.998299

Fujii H (2014) Abscisic acid implication in plant growth and stress responses. In: Tran L-S, Pal S (eds) Phytohormones: a window to metabolism, signaling and biotechnological applications. Springer, New York, pp 37-54

Gamoh K, Okamoto N, Takatsuto S, Tejima I (1990) Determination of traces of natural brassinosteroids as dansylaminophenylboronates by liquid-chromatography with fluorimetric detection. Anal Chim Acta 228(1):101-105. https://doi.org/10.1016/s0003 -2670(00)80484-5

Gołębiowska-Pikania G, Kopeć P, Surówka E, Janowiak F, Krzewska M, Dubas E, Nowicka A, Kasprzyk J, Ostrowska A, Malaga S, Hura T, Żur I (2017a) Changes in protein abundance and activity induced by drought during generative development of winter barley (Hordeum vulgare L.). J Proteomics 169(Supplement C):73-86. https://doi.org/10.1016/j.jprot.2017.07.016

Gołębiowska-Pikania G, Kopeć P, Surówka E, Krzewska M, Dubas E, Nowicka A, Rapacz M, Wójcik-Jagła M, Malaga S, Żur I (2017b) Changes in protein abundance and activity involved in freezing tolerance acquisition in winter barley (Hordeum vulgare L.). J Proteomics 169:58-72. https://doi.org/10.1016/j.jprot.2017.08.019

Gruszka D, Gorniak M, Glodowska E, Wierus E, Oklestkova J, Janeczko A, Maluszynski M, Szarejko I (2016a) A reverse-genetics mutational analysis of the barley HvDWARF gene results in identification of a series of alleles and mutants with short stature of various degree and disturbance in BR biosynthesis allowing a new insight into the process. Int J Mol Sci 17(4):600. https://doi. org/10.3390/ijms 17040600

Gruszka D, Janeczko A, Dziurka M, Pociecha E, Oklestkova J, Szarejko I (2016b) Barley brassinosteroid mutants provide an insight into phytohormonal homeostasis in plant reaction to drought stress. Front Plant Sci 7:1824. https://doi.org/10.3389/fpls.2016.01824

Gusta LV, Trischuk R, Weiser CJ (2005) Plant cold acclimation: the role of abscisic acid. J Plant Growth Regul 24(4):308-318

Hayat Q, Hayat S, Irfan M, Ahmad A (2010) Effect of exogenous salicylic acid under changing environment: a review. Environ Exp Bot 68(1):14-25. https://doi.org/10.1016/j.envexpbot.2009.08.005

Hirayama T, Shinozaki K (2007) Perception and transduction of abscisic acid signals: keys to the function of the versatile plant hormone ABA. Trends Plant Sci 12(8):343-351. https://doi.org/10.1016/j. tplants.2007.06.013
Humphreys MW, Gasior D, Lesniewska-Bocianowska A, Zwierzykowski Z, Rapacz M (2007) Androgenesis as a means of dissecting complex genetic and physiological controls: selecting useful gene combinations for breeding freezing tolerant grasses. Euphytica 158(3):337-345. https://doi.org/10.1007/s1068 1-006-9240-2

Hura T, Tyrka M, Hura K, Ostrowska A, Dziurka K (2017) QTLs for cell wall-bound phenolics in relation to the photosynthetic apparatus activity and leaf water status under drought stress at different growth stages of triticale. Mol Genet Genomics 292(2):415-433. https://doi.org/10.1007/s00438-016-1276-y

Jacquard C, Wojnarowiez G, Clement C (2003) Anther culture in barley. In: Małuszynski M, Kasha KJ, Forster BP, Szarejko I (eds) Doubled haploid production in crop plants: a manual. Springer, New York, pp 21-28

Janda T, Gondor OK, Yordanova R, Szalai G, Pal M (2014) Salicylic acid and photosynthesis: signalling and effects. Acta Physiol Plant 36(10):2537-2546. https://doi.org/10.1007/s11738-014-1620-y

Janeczko A (2016) Presence, transport and physiological activity of brassinosteroids in crop plants from Poaceae and Fabaceae family. In: Monograph of the Institute of Plant Physiology, Polish Academy of Sciences, vol 17. Institute of Plant Physiology, Polish Academy of Sciences, Cracow (in Polish)

Janeczko A, Biesaga-Kościelniak J, Oklestkova J, Filek M, Dziurka M, Szarek-Łukaszewska G, Kościelniak J (2010) Role of 24-epibrassinolide in wheat production: physiological effects and uptake. J Agron Crop Sci 196(4):311-321. https://doi.org/10.1111/j.1439037X.2009.00413.x

Janeczko A, Pociecha E, Dziurka M, Jurczyk B, Libik-Konieczny M, Oklestkova J, Novak O, Pilarska M, Filek M, Rudolphi-Skórska E (2019) Changes in content of steroid regulators during cold hardening of winter wheat-steroid physiological/biochemical activity and impact on frost resistance. Plant Physiol Biochem 139:215-228

Janeczko A, Swaczynova J (2010) Endogenous brassinosteroids in wheat treated with 24-epibrassinolide. Biol Plant 54(3):477-482. https://doi.org/10.1007/s10535-010-0084-1

Joo SH, Jang MS, Kim MK, Lee JE, Kim SK (2015) Biosynthetic relationship between C-28-brassinosteroids and C-29-brassinosteroids in rice (Oryza sativa) seedlings. Phytochemistry 111:84-90. https ://doi.org/10.1016/j.phytochem.2014.11.006

Jumali SS, Said IM, Ismail I, Zainal Z (2011) Genes induced by high concentration of salicylic acid in Mitragyna speciosa. Aust J Crop Sci 5(3):293-300

Kadlecova Z, Faltus M, Prasil I (2000) Relationship between abscisic acid content, dry weight and freezing tolerance in barley cv. Lunet. J Plant Physiol 157(3):291-297

Kalemba EM, Janowiak F, Pukacka S (2009) Desiccation tolerance acquisition in developing beech (Fagus sylvatica L.) seeds: the contribution of dehydrin-like protein. Trees Struct Funct 23(2):305-315. https://doi.org/10.1007/s00468-008-0278-8

Khan MIR, Fatma M, Per TS, Anjum NA, Khan NA (2015) Salicylic acid-induced abiotic stress tolerance and underlying mechanisms in plants. Front Plant Sci 6:462. https://doi.org/10.3389/ fpls.2015.00462

Li J, Yang P, Kang JG, Gan YT, Yu JH, Calderon-Urrea A, Lyu J, Zhang GB, Feng Z, Xie JM (2016) Transcriptome analysis of pepper (Capsicum annuum) revealed a role of 24-epibrassinolide in response to chilling. Front Plant Sci 7:1281. https://doi. org/10.3389/fpls.2016.01281

Liu W, Chen L, Zhang SL, Hu FY, Wang Z, Lyu J, Wang B, Xiang H, Zhao RP, Tian ZX, Ge S, Wang W (2019) Decrease of gene expression diversity during domestication of animals and plants. BMC Evol Biol 19:19. https://doi.org/10.1186/s1286 2-018-1340-9 
Malaga S, Krzewska M, Nowicka A, Dubas E, Ostrowska A, WojcikJagla M, Hura T, Rapacz M, Żur I (2016) Increasing tolerance to abiotic stresses by haplodiploidization in Hordeum vulgare. In: Grzesiak M, Rzepka A, Hura T, Grzesiak S (eds) Plant functioning under environmental stress. The Franciszek Górski Institute of Plant Physiology, Polish Academy of Sciences, Cracow, pp 37-46

Moravcova S, Tuma J, Ducaiova ZK, Waligorski P, Kula M, Saja D, Slomka A, Baba W, Libik-Konieczny M (2018) Influence of salicylic acid pretreatment on seeds germination and some defence mechanisms of Zea mays plants under copper stress. Plant Physiol Biochem 122:19-30. https://doi.org/10.1016/j.plaphy.2017.11.007

Murelli C, Rizza F, Albini FM, Dulio A, Terzi V, Cattivelli L (1995) Metabolic changes associated with cold-acclimation in contrasting cultivars of barley. Physiol Plant 94(1):87-93

Mutlu S, Karadagoglu O, Atici O, Nalbantoglu B (2013) Protective role of salicylic acid applied before cold stress on antioxidative system and protein patterns in barley apoplast. Biol Plant 57(3):507-513. https://doi.org/10.1007/s10535-013-0322-4

Nambara E, Okamoto M, Tatematsu K, Yano R, Seo M, Kamiya Y (2010) Abscisic acid and the control of seed dormancy and germination. Seed Sci Res 20(2):55-67. https://doi.org/10.1017/s096025851 0000012

Oklestkova J, Tarkowska D, Eyer L, Elbert T, Marek A, Smrzova Z, Novak O, Franek M, Zhabinskii VN, Strnad M (2017) Immunoaffinity chromatography combined with tandem mass spectrometry: a new tool for the selective capture and analysis of brassinosteroid plant hormones. Talanta 170:432-440. https://doi.org/10.1016/j. talanta.2017.04.044

Parent B, Hachez C, Redondo E, Simonneau T, Chaumont F, Tardieu F (2009) Drought and abscisic acid effects on aquaporin content translate into changes in hydraulic conductivity and leaf growth rate: a trans-scale approach. Plant Physiol 149(4):2000-2012. https://doi. org/10.1104/pp.108.130682

Pociecha E, Dziurka M, Oklestkova J, Janeczko A (2016) Brassinosteroids increase winter survival of winter rye (Secale cereale L.) by affecting photosynthetic capacity and carbohydrate metabolism during the cold acclimation process. Plant Growth Regul 80(2):127135. https://doi.org/10.1007/s10725-016-0149-Z

Pociecha E, Płażek A, Janowiak F, Waligórski P, Zwierzykowski Z (2009) Changes in abscisic acid, salicylic acid and phenylpropanoid concentrations during cold acclimation of androgenic forms of Festulolium (Festuca pratensis $\times$ Lolium multiflorum) in relation to resistance to pink snow mould (Microdochium nivale). Plant Breed 128(4):397-403. https://doi.org/10.1111/j.1439-0523.2009.01664.x

Popova LP, Tsonev TD, Lazova GN, Stoinova ZG (1996) Droughtand ABA-induced changes in photosynthesis of barley plants. Physiol Plant 96(4):623-629. https://doi.org/10.103 4/j.1399-3054.1996.960411.x

Quarrie SA, Whitford PN, Appleford NEJ, Wang TL, Cook SK, Henson IE, Loveys BR (1988) A monoclonal antibody to (S) abscisic acid: its characterisation and use in a radioimmunoassay for measuring abscisic acid in crude extracts of cereal and lupin leaves. Planta 173:330-339

Rajashekar CB (2016) Molecular responses and mechanisms of plant adaptation to cold and freezing stress. In: Huang B (ed) Plant-environment interactions. CRC Press, Boca Raton, pp 47-68

Rapacz M, Sasal M, Gut M (2011) Chlorophyll fluorescence-based studies of frost damage and the tolerance for cold-induced photoinhibition in freezing tolerance analysis of triticale (xTriticosecale Wittmack). J Agron Crop Sci 197(5):378-389. https://doi. org/10.1111/j.1439-037X.2011.00472.x

Rapacz M, Tyrka M, Gut M, Mikulski W (2010) Associations of PCR markers with freezing tolerance and photosynthetic acclimation to cold in winter barley. Euphytica 175(3):293-301. https://doi. org/10.1007/s10681-010-0127-x
Rapacz M, Tyrka M, Kaczmarek W, Gut M, Wolanin B, Mikulski W (2008) Photosynthetic acclimation to cold as a potential physiological marker of winter barley freezing tolerance assessed under variable winter environment. J Agron Crop Sci 194(1):61-71. https:// doi.org/10.1111/j.1439-037X.2007.00292.x

Reid JB, Symons GM, Ross JJ (2010) Regulation of gibberellin and brassinosteroid biosynthesis by genetic, environmental and hormonal factors. In: Davies PJ (ed) Plant hormones: biosynthesis, signal transduction, action! Springer, Dordrecht, pp 179-203. https://doi. org/10.1007/978-1-4020-2686-7_9

Sadura I, Janeczko A (2018) Physiological and molecular mechanisms of brassinosteroid-induced tolerance to high and low temperature in plants. Biol Plant 62(4):601-616. https://doi.org/10.1007/s1053 5-018-0805-4

Sadura I, Pociecha E, Dziurka M, Oklestkova J, Novak O, Gruszka D, Janeczko A (2019) Mutations in the HvDWARF, HvCPD and HvBRI1 genes-involved in brassinosteroid biosynthesis/signalling: altered photosynthetic efficiency, hormonal homeostasis and tolerance to high/low temperatures in barley. J Plant Growth Regul. https ://doi.org/10.1007/s00344-019-09914-z

Schmid K, Kilian B, Russell J (2018) Barley domestication, adaptation and population genomics. In: Stein N, Muehlbauer GJ (eds) The barley genome. Springer, Cham, pp 317-336. https://doi. org/10.1007/978-3-319-92528-8_17

Seiler C, Harshavardhan VT, Reddy PS, Hensel G, Kumlehn J, EschenLippold L, Rajesh K, Korzun V, Wobus U, Lee J, Selvaraj G, Sreenivasulu N (2014) Abscisic acid flux alterations result in differential abscisic acid signaling responses and impact assimilation efficiency in barley under terminal drought stress. Plant Physiol 164(4):1677-1696. https://doi.org/10.1104/pp.113.229062

Tasgin E, Atici O, Nalbantoglu B (2003) Effects of salicylic acid and cold on freezing tolerance in winter wheat leaves. Plant Growth Regul 41(3):231-236. https://doi.org/10.1023/B:GROW.00000 07504.41476.c2

Tommasini L, Svensson JT, Rodriguez EM, Wahid A, Malatrasi M, Kato K, Wanamaker S, Resnik J, Close TJ (2008) Dehydrin gene expression provides an indicator of low temperature and drought stress: transcriptome-based analysis of barley (Hordeum vulgare L.). Funct Integr Genomics 8(4):387-405

Trejo CL, Clephan AL, Davies WJ (1995) How do stomata read abscisic acid signals? Plant Physiol 109:803-811

Verma V, Ravindran P, Kumar PP (2016) Plant hormone-mediated regulation of stress responses. BMC Plant Biol. https://doi.org/10.1186/ s12870-016-0771-y

Vicente MRS, Plasencia J (2011) Salicylic acid beyond defence: its role in plant growth and development. J Exp Bot 62(10):3321-3338. https ://doi.org/10.1093/jxb/err031

Vishwakarma K, Upadhyay N, Kumar N, Yadav G, Singh J, Mishra RK, Kumar V, Verma R, Upadhyay RG, Pandey M, Sharma S (2017) Abscisic acid signaling and abiotic stress tolerance in plants: a review on current knowledge and future prospects. Front Plant Sci. https://doi.org/10.3389/fpls.2017.00161

Vlot AC, Dempsey DA, Klessig DF (2009) Salicylic acid, a multifaceted hormone to combat disease. Annu Rev Phytopathol 47:177-206. https://doi.org/10.1146/annurev.phyto.050908.135202

Walker-Simmons MK, Abrams SR (1991) Use of ABA immunoassays. In: Davies WJ, Jones HG (eds) Abscisic acid, physiology and biochemistry. Bios Scientific Publishers, Oxford, pp 53-63

Walker DJ, Romero P, Correal E (2010) Cold tolerance, water relations and accumulation of osmolytes in Bituminaria bituminosa. Biol Plant 54(2):293-298. https://doi.org/10.1007/s10535-010-0051-x

Wani SH, Kumar V, Shriram V, Sah SK (2016) Phytohormones and their metabolic engineering for abiotic stress tolerance in crop plants. Crop J 4(3):162-176. https://doi.org/10.1016/j.cj.2016.01.010

Xue GP, Loveridge CW (2004) HvDRF1 is involved in abscisic acidmediated gene regulation in barley and produces two forms of AP2 
transcriptional activators, interacting preferably with a CT-rich element. Plant J 37(3):326-339

Yuan S, Lin HH (2008) Role of salicylic acid in plant abiotic stress. Z Naturforsch C 63(5-6):313-320

Zhang JH, Jia WS, Yang JC, Ismail AM (2006) Role of ABA in integrating plant responses to drought and salt stresses. Field Crop Res 97(1):111-119

Zullo MAT, Kohout L (2004) Semisystematic nomenclature of brassinosteroids. Plant Growth Regul 42(1):15-28. https://doi.org/10.1023/ b:grow.0000014898.30414.33
Żur I, Dubas E, Krzewska M, Waligórski P, Dziurka M, Janowiak F (2015) Hormonal requirements for effective induction of microspore embryogenesis in triticale (x Triticosecale Wittm.) anther cultures. Plant Cell Rep 34(1):47-62. https://doi.org/10.1007/s0029 9-014-1686-4

Publisher's Note Springer Nature remains neutral with regard to jurisdictional claims in published maps and institutional affiliations. 